http://jmscr.igmpublication.org/home/ ISSN (e)-2347-176x ISSN (p) 2455-0450 crossref DOI: https://dx.doi.org/10.18535/jmscr/v10i2.05

\title{
Immediate Effect of Dry Needling For Semispinalis Capitis in a Patient with Non-Specific Neck Pain- A Case Report
}

\author{
Authors \\ Sakshi Shah ${ }^{1}$, Dr Shrikant Mhase ${ }^{2}$, Syeda Sameeha Tartil ${ }^{3}$ \\ ${ }^{1}$ Intern, MGM School of Physiotherapy, Aurangabad, Maharashtra, India \\ ${ }^{2}$ Assistant Professor, MGM School of Physiotherapy, Aurangabad, Maharashtra, India \\ ${ }^{3}$ Intern, MGM School of Physiotherapy, Aurangabad, Maharashtra, India
}

\begin{abstract}
Background: Chronic non-specific neck pain is considered to be a common cervical spine disorder which usually affects the patient's day to day activities. Non-specific neck pain affects the deep cervical musculature frequently, thus causing pain. Dry needling is an invasive technique used by physical therapists and other professionals that involves use of a thin needle without an injectate to relieve pain. This study presents the use of this invasive procedure to facilitate pain reduction on an immediate basis in a case of chronic non-specific neck pain.

Case Description: A 24 year old female presented with non-specific neck pain for last 4 years, responded poorly to medications and previous physiotherapy interventions. Her pain aggravated in past 1 month which affected her functional activities for which she was referred to take physiotherapy treatment.

Procedure: Dry needling of semispinalis capitis muscle was used to reduce pain, which is a less wellknown procedure.

Result: The result was calculated based on the pre-treatment and post-treatment sessions using NPRS and NDI that showed significant changes in the pain intensity and disability scores. Prior to the treatment, the score of NPRS for intensity of pain was 8 which subsequently reduced to 1 after 2 sessions of treatment. NDI scores varied from $52 \%$ pre-treatment to $8 \%$ post-treatment.

Conclusion: There is immediate effect of dry needling for semispinalis capitis in a patient with chronic non-specific neck pain which aids in pain relief, leading to improved functional activities of daily living and speeding up positive physical therapy outcomes.

Limitations: Since this is a case report, it cannot be generalised for a large group of population. Further research may be required to fully comprehend the usage of dry needling for semispinalis capitis, and its efficacy might be monitored over time to provide a better understanding of the treatment parameters.

Keywords: Neck pain, dry needling, semispinalis capitis, case report.
\end{abstract}

\section{Introduction}

The prevalence of neck pain is increasing day by day. Non-specific neck pain (NSNP) is one of the most common cervical spine disorders that affects $30 \%$ to $50 \%$ of the general population, with about $10 \%$ of these patients experiencing chronic neck pain. $^{1}$
Patients with chronic neck pain have lower activity in the semispinalis and multifidus muscles. ${ }^{2}$ There is presence of semispinalis capitis muscle atrophy in patients with chronic nonspecific neck pain. ${ }^{3}$ Semispinalis capitis is a long paired muscle in the deep layer of the back muscles. It is the superior and largest component 
of semispinalis muscles, which is divided into three parts. It aids in the extension of the head, cervical, and thoracic spines by working with the obliquus capitis superior, splenius, trapezius, rectus capitis posterior major, and rectus capitis posterior minor muscles. ${ }^{4,5}$ In most chronic neck pain sufferers, the cross sectional area of deep cervical extensors musculature is altered, especially the semispinalis and cervical multifidus muscles. ${ }^{6-8}$

Forward head is a frequent postural compensation that occurs which causes suboccipital muscles to extend, thus putting strain on semispinalis capitis and levator scapulae muscles. Deficits in the muscle activity of the cervical spine may lead to inadequate joint movement control, repetitive microtrauma and eventually causing pain. ${ }^{9}$

Dry needling is a skilful intervention that utilises a thin filiform needle which stimulates the muscles, fascia, connective tissue, myofascial trigger points by penetrating into these structures via the skin for the treatment of neuromusculoskeletal pain and movement impairments. ${ }^{10}$ Dry needling may not affect all the components of central sensitization but it is likely that the local pain and the referred pain will decrease along with improvements in muscle blood flow, oxygenation, muscle activation patterns and joint range of motion. ${ }^{11-13}$

The goal of using this treatment approach was to provide pain relief and lessen the disability caused by neck pain.

\section{Patient Information}

A 24 year old female, student by occupation, presented with a chief complaint of neck pain since last 4 years, which had aggravated since past 1 month. Patient reported chronic neck pain which was continuous in nature with an intensity of 8 on NPRS on activity and 6 on NPRS at rest. The pain aggravated during the neck movements, cervical extension was more painful as compared to cervical flexion. She received analgesics as well as physical therapy for the same and had a poor response to previous interventions. There was no other significant history found.

\section{Clinical Findings}

Physical examination was done and all of her vital parameters including temperature, pulse rate, SPO2, blood pressure were within the normal limits. Patient reported of pain which was 8 on NPRS. Patient showed marked postural deviations which involved forward head and protracted shoulders. On palpation, grade 2 tenderness was found over semispinalis capitis. Cervical range of motion was incomplete and painful for extension. Range of motion for cervical flexion was painfree and complete. Cervical side flexion was painfree and complete. Resisted isometrics for cervical extensors were weak and painful.

\section{Diagnostic Assessment}

There was no radiological diagnostic testing done. The diagnosis of non-specific neck pain was determined based on subjective and objective examination.

\section{Therapeutic Intervention}

Dry needling for semispinalis capitis was done on both the sides using filiform needles. The patient was in prone position with the neck outside the plinth with neck in slight flexion. A $40 \mathrm{~mm}$ filiform needle was inserted parallel to the muscle fibres of semispinalis capitis at an angle of $25^{\circ}$ for duration of 10 minutes on each side. Later, it was followed by cryotherapy for 15 minutes. Same procedure was followed after 48 hours.

\section{Follow Up and Outcome Measures}

Outcome measures that were used consisted of Numerical Pain Rating Scale (NPRS), Range of Motion (ROM) and Neck Disability Index. There was significant effect of dry needling in reducing the pain and showed slight increase in cervical ROM. There was a change in the score of Neck Disability Index as well. After $1^{\text {st }}$ session of the treatment, pain reduced to an intensity of 3 on NPRS and following the end of $2^{\text {nd }}$ session that was post 48 hours of the $1^{\text {st }}$ session, patient complained of pain as 1 on NPRS. 


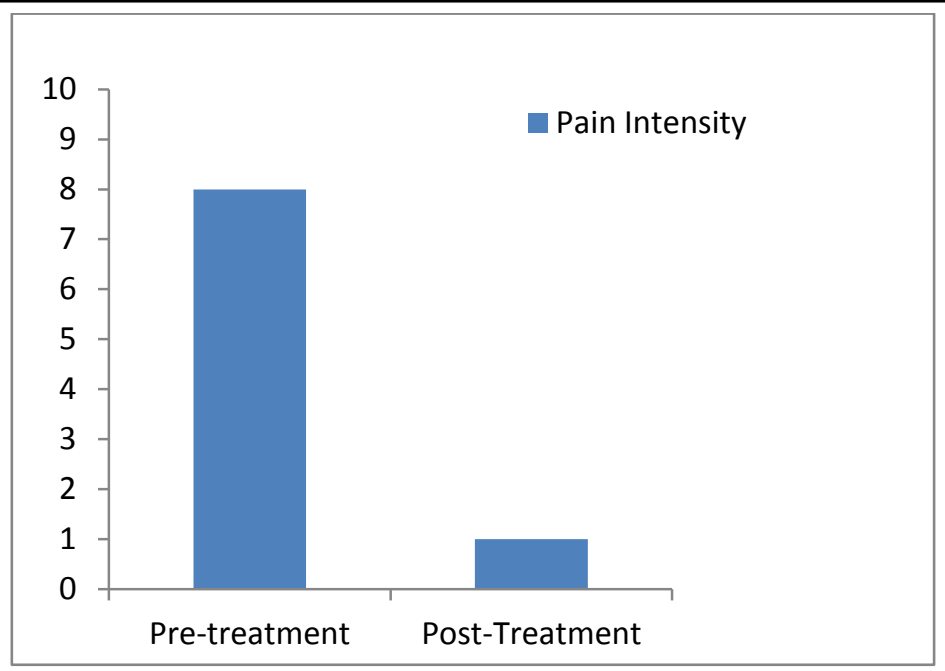

Fig 1- Graphical Representation of Pain Intensity using NPRS

There was increase in cervical extension from $56^{\circ}$ to $64^{\circ}$ at the end of the treatment.

There was significant improvement in the Neck Disability Index scores. Following are the changes found in score of Neck Disability Index -

Table 1- Difference in NDI Scores

\begin{tabular}{|l|c|c|c|}
\hline $\begin{array}{l}\text { Items of Neck Disability } \\
\text { Index }\end{array}$ & $\begin{array}{c}\text { Pre Dry Needling } \\
\text { (Before } 1^{\text {st }} \text { session) }\end{array}$ & $\begin{array}{c}\text { Post Dry Needling } \\
(\text { End of 2 }\end{array}$ & $\begin{array}{c}\text { Follow-up } \\
\text { (After 15 days) }\end{array}$ \\
\hline Pain Intensity & 4 & 0 & 0 \\
\hline Personal Care & 1 & 0 & 0 \\
\hline Lifting & 3 & 1 & 1 \\
\hline Reading & 3 & 1 & 0 \\
\hline Headache & 2 & 0 & 1 \\
\hline Concentration & 3 & 1 & 0 \\
\hline Work & 2 & 1 & 0 \\
\hline Driving & 2 & 0 & 0 \\
\hline Sleeping & 3 & 0 & 0 \\
\hline Recreation & 3 & 0 & 2 \\
\hline Total Score & 26 & 4 & $4 \%$ \\
\hline NDI score & $52 \%$ & $8 \%$ & 0 \\
\hline
\end{tabular}

\section{Intervention Adherence and Patient Tolerability}

The patient was co-operative and adhered well to the treatment.

\section{Adverse and Unanticipated Events}

There is no presence of any adverse and unanticipated events.

\section{Discussion}

This case report, to the best of our knowledge, is unique among previous research studies since it is an attempt to illustrate the applicability of dry needling for semispinalis capitis muscle in chronic non-specific neck pain.
There is poor joint control movement and microtrauma resulting in chronic neck pain due to damage to the deep cervical extensor musculature. ${ }^{9}$ Studies have reported that there is reduced activity of the semispinalis and cervical multifidus in patients with chronic neck pain as compared to healthy population. ${ }^{2}$

The physiological effects of dry needling is a combination of cortical and peripheral effects; cortical effects including psychological and placebo mechanisms while peripheral effects include spinal and supraspinal mechanisms. These mechanisms include gate control theory and endogenous opioid mechanisms, respectively. ${ }^{14}$ 
Studies have also suggested that dry needling is hypothesized to stimulate the serotonergic (5-HT) and the noradrenergic descending inhibitory systems, resulting in pain reduction. The studies have also reported that dry needling may excite the enkephalinergic inhibitory dorsal horn interneurons by stimulating nociceptive fibres. ${ }^{15}$

In non-specific chronic neck pain, there is involvement of deep cervical extensors which involves the semispinalis capitis muscle, where pain limits the range of motion. Thus, this approach of dry needling for semispinalis capitis in cases of non-specific neck pain will assist in reducing pain and regain the normal functional movement.

\section{Conclusion}

This study determined the effect of dry needling for semispinalis capitis in a case of chronic nonspecific neck pain and showed that it provides immediate effect to the patient by facilitating pain relief and slight increase in cervical ROM which aids in improving activities of daily living and improved quality of life. Thus, this case study concludes that in patients suffering from chronic non-specific neck pain, dry needling treatments have the potential to speed up positive physical therapy outcomes.

\section{Limitations and Recommendations}

The findings cannot be generalised to a wider a sample size because this is a case study. More research is required to better understand the use of dry needling for semispinalis capitis and its efficacy might be examined over time to offer a better knowledge of the treatment parameters.

Patient Perspective- The patient found significant amount of pain relief after 2 sessions of treatment.

Informed Consent- Informed consent was taken from the patient.

Conflict of Interest- Nil.

\section{References}

1. Hogg-Johnson S, Van Der Velde G, Carroll LJ, Holm LW, Cassidy JD, Guzman J, Côté P, Haldeman S, Ammendolia C, Carragee E, Hurwitz E. The burden and determinants of neck pain in the general population. European Spine Journal. 2008 Apr;17(1):39-51.

2. O'Leary S, Cagnie B, Reeve A, Jull G, Elliott JM. Is there altered activity of the extensor muscles in chronic mechanical neck pain? A functional magnetic resonance imaging study. Archives of physical medicine and rehabilitation. 2011 Jun 1;92(6):929-34.

3. Rezasoltani A, Ahmadipoor A, KhademiKalantari K, Javanshir K. The sign of unilateral neck semispinalis capitis muscle atrophy in patients with chronic nonspecific neck pain. Journal of back and musculoskeletal rehabilitation. 2012 Jan 1;25(1):67-72.

4. Netter, F. (2019). Atlas of Human Anatomy (7th ed.). Philadelphia, PA: Saunders.

5. Standring, S. (2016). Gray's Anatomy (41tst ed.). Edinburgh: Elsevier Churchill Livingstone.

6. Kristjansson E. Reliability of ultrasonography for the cervical multifidus muscle in asymptomatic and symptomatic subjects. Man Ther. 2004;9(2):83-88.

7. Elliott J, Jull G, Noteboom JT, Darnell R, Galloway G, Gibbon WW. Fatty infiltration in the cervical extensor muscles in persistent whiplash-associated disorders: a magnetic resonance imaging analysis. Spine. 2006 Oct 15;31(22):E84755.

8. Elliott J, Jull G, Noteboom JT, Galloway G. MRI study of the cross-sectional area for the cervical extensor musculature in patients with persistent whiplash associated disorders (WAD). Manual therapy. 2008 Jun 1;13(3):258-65. 
9. Falla D, Farina D. Neural and muscular factors associated with motor impairment in neck pain. Current rheumatology reports. 2007 Dec 1;9(6):497-502.

10. American Physical Therapy Association, American Physical Therapy Association. Description of dry needling in clinical practice: an educational resource paper. Alexandria, VA: American Physical Therapy Association. 2013.

11. Cagnie B, Barbe T, De Ridder E, Van Oosterwijck J, Cools A, Danneels L. The influence of dry needling of the trapezius muscle on muscle blood flow and oxygenation. Journal of manipulative and physiological therapeutics. 2012 Nov 1;35(9):685-91.

12. Cagnie B, Dewitte V, Barbe T, Timmermans F, Delrue N, Meeus $M$. Physiologic effects of dry needling. Current pain and headache reports. 2013 Aug 1;17(8):348.

13. Dommerholt J. Dry needling-peripheral and central considerations. Journal of Manual \& Manipulative Therapy. 2011 Nov 1;19(4):223-7.

14. Linde K. Allais G. Brinkhaus B. Manheimer E. Vickers A. White AR. Acupuncture for tension-type headache. Cochrane Database of Systematic Reviews. 2009;1.

15. Cagnie B, Dewitte V, Barbe T, Timmermans F, Delrue N, Meeus $M$. Physiologic effects of dry needling. Current pain and headache reports. 2013 Aug 1;17(8):348.

\section{List of Abbreviations}

ROM- Range of Motion

NDI- Neck Disability Index

NPRS- Numerical Pain Rating Scale 